Check for updates

Cite this: RSC Adv., 2017, 7, 54522

\title{
Fabrication of a new metal-organic framework for sensitive sensing of nitroaromatics and efficient dye adsorption $\uparrow$
}

\author{
Wei-Ping Wu, ${ }^{\text {*a }}$ Jian Wu, Jian-Qiang Liu, (D) *c Manoj Trivedi (D) ${ }^{d}$ \\ and Abhinav Kumar (D) *e
}

\begin{abstract}
The hydrothermal reaction of $\mathrm{Cd}(\mathrm{II})$ salt with rigid tetracarboxylate ligand, terphenyl-3,3" $5,5^{\prime \prime}$-tetracarboxylic acid $\left(\mathrm{H}_{4} \mathrm{~L}\right)$ produced a new metal-organic framework (MOF) $\left\{\left[\mathrm{Cd}_{2}(\mathrm{~L})(\mathrm{DMF})_{3}\right] \cdot 0.5 \mathrm{DMF}\right\}_{n}(1)$. Single crystal $\mathrm{X}$-ray diffraction showed that MOF 1 possesses a 3D microporous framework with 4-connected Dia topology which is based on $\left\{\mathrm{Cd}_{2}\left(\mathrm{CO}_{2}\right)_{4}\right\}$ subunits. MOF 1 is a promising dual functional sensor with high selectivity and sensitivity for the detection and recognition of nitroaromatics (NACs) and $\mathrm{Fe}^{3+}$ ions via alleviation of its fluorescence intensity. Furthermore, 1 also has an excellent capacity to adsorb methylene blue (MB) with high selectivity, and it retains almost similar adsorption performance after being recycled several times. The observed decrease in fluorescence intensity of 1 in the presence of NACs has been addressed by theoretical calculations which indicate that the intensity alleviation of 1 in the presence of NACs can be attributed to an electron and resonance energy transfer between 1 and nitro analytes.
\end{abstract}

Received 11th October 2017

Accepted 23rd November 2017

DOI: 10.1039/c7ra11221a

rsc.li/rsc-advances

The continuous and exponential misuse of nitro-aromatic compounds (NACs) as explosives has led to countless economic losses to the world because of their explosive nature. ${ }^{1}$ Thus, precise and effective detection of these explosive compounds is vital for civil security. The traditional detection methods for detecting these molecules by using state-of-the-art analytical instruments have emerged and they have displayed good performance.,3 However, these methods suffer from drawbacks viz. high equipment costs and poor portability which prevent their widespread applications. ${ }^{4}$ Recently, luminescent metal-organic frameworks (LMOFs) have been widely employed in building optical sensors because they can encapsulate the analytes and exhibit luminescence quenching or spectrum shifting. Hence LMOFs have gained a reputation as being

${ }^{a}$ College of Chemistry and Environmental Engineering, Sichuan University of Science \& Engineering, Zigong 643000, P. R. China. E-mail: wuweipingzg@126.com

${ }^{b}$ Guangxi Key Laboratory of Chemistry and Engineering of Forest Products, Guangxi University for Nationalities, College of Chemistry and Chemical Engineering, Nanning, Guangxi 530006, China

'Dongguan Key Laboratory of Drug Design and Formulation Technology, Key Laboratory of Research and Development of New Medical Materials of Guangdong Medical University, School of Pharmacy, Guangdong Medical University, Dongguan, 523808, P. R. China. E-mail: jianqiangliu2010@126.com

${ }^{d}$ Department of Chemistry, University of Delhi, Delhi, India

${ }^{e}$ Department of Chemistry, Faculty of Science, University of Lucknow, Lucknow 226 007, India. E-mail: abhinavmarshal@gmail.com; kumar_abhinav@lkouniv.ac.in; Fax: +91-769-22896560; Tel: +91-769-22896560

$\dagger$ Electronic supplementary information (ESI) available. CCDC 1556532. For ESI and crystallographic data in CIF or other electronic format see DOI: 10.1039/c7ra11221a cheap, fast and portable systems for the effective detection of analytes viz. ions and molecules. ${ }^{5}$ Also, it has been established that the luminescence properties of LMOFs can be tuned by using different ligands having rigid organic moieties and the resultant LMOFs can in turn be utilized for the specific detection of ions and molecules. ${ }^{6-10}$

The waste-water discharge always comprises of significant amount of organic dyes which imposes significant threat to the environment and human health because of the toxic and carcinogenic properties associated with these organic dyes. ${ }^{11}$ Until now, many approaches for the removal of dyes for example using activated carbons and zeolites etc. have been applied during the industrial processing of the waste-water. ${ }^{11}$ But they display poor performance when selective removal of the targeted organic dye from waste-water containing mixture of organic molecules is concerned..$^{12}$ Therefore, the design and synthesis of porous MOFs having selective adsorption of molecule for waste-water treatment applications is highly desirable. ${ }^{12}$

With these viewpoints and in our continuous quest for the development of new LMOFs ${ }^{13}$ for sensing applications for the detection nitro-aromatics as well as dye-adsorption, in the presented work, we had used a rigid multicarboxylate terphenyl$3,3^{\prime \prime}, 5,5^{\prime \prime}$-tetracarboxylic acid $\left(\mathrm{H}_{4} \mathrm{~L}\right)$ to fabricate $\mathrm{d}^{10}$-based $\mathrm{Cd}(\mathrm{II})$ LMOFs. The use of this ligand is based on the following associated features: ${ }^{14}$ (a) $\mathrm{H}_{4} \mathrm{~L}$ comprises of four carboxylic acid groups and therefore have multiple coordination sites and hence can display varied coordination modes and in-turn is capable of yielding high dimensional frameworks; (b) the use of symmetry linkers sometimes has been shown to be an effective 
way to suppress framework interpenetration and promote the formation of porous materials. ${ }^{3 c}$ In this work Cd(II) MOF 1 possess a 3D framework having 4-connected Dia topology and can be used as a luminescent sensor for the detection of nitroaromatics (NACs) and $\mathrm{Fe}^{3+}$ as well as an effective adsorbent for methylene blue (MB).

\section{Materials and method}

\section{General considerations}

All the chemicals were available commercially and have been used without any further purification. Powder X-ray diffraction (PXRD) data for 1 was collected using Bruker D8 Advance X-ray diffractometer equipped with $\mathrm{Cu}-\mathrm{K} \alpha$ radiation $(\lambda=1.5418 \AA)$ at $50 \mathrm{kV}, 20 \mathrm{~mA}$ with a scanning rate of $6^{\circ} \mathrm{min}^{-1}$ and a step size of $0.02^{\circ}$. The simulated powder patterns of 1 were obtained using Mercury 2.0 which was compared with the experimental PXRD to check the purity and homogeneity of $\mathbf{1}$ in bulk. FT-IR spectra as $\mathrm{KBr}$ pellet were measured using a Nicolet Impact 750 FTIR in the range of $4000-400 \mathrm{~cm}^{-1}$. Thermogravimetric analysis was performed under nitrogen atmosphere from room temperature to $650{ }^{\circ} \mathrm{C}$ at a heating rate of $10{ }^{\circ} \mathrm{C} \mathrm{min}^{-1}$, using a SDT Q600 thermogravimetric analyzer.

\section{X-ray crystallography}

The single crystal X-ray diffraction data collection for $\mathbf{1}$ was carried out using Bruker SMART APEX diffractometer that was equipped with a graphite monochromated Mo-K $\alpha$ radiation $(\lambda=$ $0.71073 \AA$ ) by using an $\omega$-scan technique. The intensities of the absorption effects were corrected by using SADABS. The structure was solved by direct method (SHLEXS-2014) and refined by fullmatrix least-squares procedure based on $F^{2}$ (SHELXL-2014). ${ }^{15}$ All the hydrogen atoms were generated geometrically and refined isotropically using the riding model. The MOF 1 was weakly diffracting in nature and hence gave poor data. Thus, restraints were applied during the refinement of the structure using the restraint commands (SIMU, SADI and EADP etc.), which have been used for some unreasonable atoms. Because guest molecules (DMF) in the channels of 1 were highly disordered and those could not be modelled properly, the SQUEEZE routine of PLATON was applied to remove their contributions. ${ }^{16}$ All non-hydrogen atoms were refined with anisotropic displacement parameters. Crystallographic details and selected bond dimensions for $\mathbf{1}$ are listed in Tables S1 and S2, $\uparrow$ respectively. CCDC number: 1556532.

\section{Synthesis of $\left.\left[\mathrm{Cd}_{2}(\mathrm{~L})(\mathrm{DMF})_{3}\right] \cdot 0.5 \mathrm{DMF}\right\}_{n}(1)$}

A mixture of terphenyl-3,3" $, 5,5^{\prime \prime}$-tetracarboxylic acid $\left(\mathrm{H}_{4} \mathrm{~L}\right)$ $(0.1 \mathrm{mmol}, 0.018 \mathrm{~g})$ and $\mathrm{Cd}\left(\mathrm{NO}_{3}\right)_{2} \cdot 6 \mathrm{H}_{2} \mathrm{O}(0.2 \mathrm{mmol}, 0.042 \mathrm{~g})$ was dissolved in DMF ( $2 \mathrm{~mL}$ ) in a screw-capped vial and two drops of $\mathrm{HNO}_{3}(65 \%, \mathrm{aq})$ was added to the mixture. The obtained solution was placed in a $25 \mathrm{~mL}$ vial and heated to $85^{\circ} \mathrm{C}$ for $72 \mathrm{~h}$. After that the reaction mixture was cooled to room temperature at a rate of $2{ }^{\circ} \mathrm{C} \mathrm{h}^{-1}$. Colorless block crystals of 1 were obtained in $39 \%$ yield based on $\mathrm{Cd}$. Anal. (\%) calcd for $\mathrm{C}_{32.5} \mathrm{H}_{34.5} \mathrm{O}_{11.5} \mathrm{~N}_{3.5} \mathrm{Cd}_{2}$ : C, $44.21 \%$; H, 3.94\%; N, 5.55\%; found: C, $43.88 \%$; H, 3.83\%; N,
5.46\%. IR: 2340 (m); 1646 (vs); 1598 (m); 1540 (vs); 1345 (vs); 1288 (m); 1106 (m); 916 (m); 778 (v); 725 (v); 661 (m).

\section{Computational details}

The mechanism associated with the alleviation in the fluorescence intensity of $\mathbf{1}$ in the presence of NACs have been proposed using density functional theory (DFT) calculations. The optimized molecular geometries different analytes, the ligand $\mathrm{H}_{4} \mathrm{~L}$ as well as MOF 1 were calculated using the B3LYP exchange-correlation functional. ${ }^{17 a, b}$ The $6-31 G^{* *}$ basis set for all the atoms other than Cd was used and for Cd LANL2DZ basis set was employed. All the calculations were performed using Gaussian 09 programme. ${ }^{17 c}$

\section{Results and discussion}

\section{$\left.\left[\mathrm{Cd}_{2}(\mathrm{~L})(\mathrm{DMF})_{3}\right] \cdot 0.5 \mathrm{DMF}\right\}_{n}(1)$}

The asymmetric unit in MOF 1 comprises of one $\mathrm{L}^{4-}$ ligand, two Cd(II) ions, three coordinated DMF molecules, and a free half DMF molecule (Fig. 1a). There are two crystallographically independent $\mathrm{Cd}(\mathrm{II})$ centers ( $\mathrm{Cd} 1$ and $\mathrm{Cd} 2$ ) existing in different coordination environments. Cd1 is coordinated to four oxygen atoms of the two chelating carboxylate groups $(\mathrm{O} 1, \mathrm{O} 2, \mathrm{O} 3$ and $\mathrm{O} 4)$ and two oxygen atoms from two bridging-bidentate carboxylate groups (O5 and O7) thereby completing a distorted octahedral environment (Fig. 1a). The $\mathrm{Cd} 2$ center also possess distorted octahedral coordination geometry in which the axial sites are occupied by one oxygen atom from one bridging-bidentate carboxylate group (O6) and one oxygen atom from coordinated DMF (O10). The equatorial positions are occupied by $\mathrm{O} 1$ and $\mathrm{O} 8$ atoms from two $\mathrm{L}^{4-}$ linkers and $\mathrm{O} 9$ and $\mathrm{O} 11$ of DMF molecules. The two $\mathrm{L}^{4-}$ linkers lie across twofold axes and display two coordination modes (Scheme S1 $\dagger$ ). The two unique Cd(II) centers are bridged by three carboxylate groups which leads to the formation of a dinuclear cluster (Fig. 1b). The $\mathrm{L}^{4-}$ ligands bridges the $\mathrm{Cd}_{2}\left(\mathrm{CO}_{2}\right)_{4}$ clusters to generate a $3 \mathrm{D}$ network (Fig. $1 \mathrm{c}$ and $\mathrm{S} 1 \dagger$ ). Each cluster is coordinated to four L ligands, and each L ligand binds to four clusters. Thus the cluster and both unique $\mathrm{L}^{4-}$ ligands act as 4-c nodes, and generate an underlying network with the diamond topology (Fig. 1d). ${ }^{18,19}$ There is the formation of a 3D framework that exhibits elliptical channels of dimension 8.1 $\times 10.2 \AA^{2}$ along the $c$ crystallographic direction (atom-to-atom separations). The disordered DMF solvent molecules are located in these channels. The differences in the topologies of the MOFs synthesized using $\mathrm{H}_{4} \mathrm{~L}$ ligand can be attributed to the variation in the feature of cluster modes. ${ }^{20}$ The calculations using PLATON indicates that the effective free volume in 1 is $\sim 68.7 \%{ }^{16}$

The thermogravimetric analysis indicates that the framework of 1 is stable up to $350{ }^{\circ} \mathrm{C}$ (Fig. S2 $\dagger$ ). The permanent porosity of the framework of 1 had been estimated using $\mathrm{N}_{2}$ adsorption profile (Fig. $\mathrm{S} 3 \dagger$ ) which indicates that $\mathbf{1}$ is a microporous material with pore volume of $115.50 \mathrm{~cm}^{3}$ (STP) $\mathrm{g}^{-1}$ and the BET surface area is $320.5 \mathrm{~m}^{2} \mathrm{~g}^{-1} .^{21}$

\section{Fluorescence sensing}

The fluorescence properties of both 1 and $\mathrm{H}_{4} \mathrm{~L}$ ligand were investigated in the solid state. On excitation at $\sim 280 \mathrm{~nm}$, both 1 

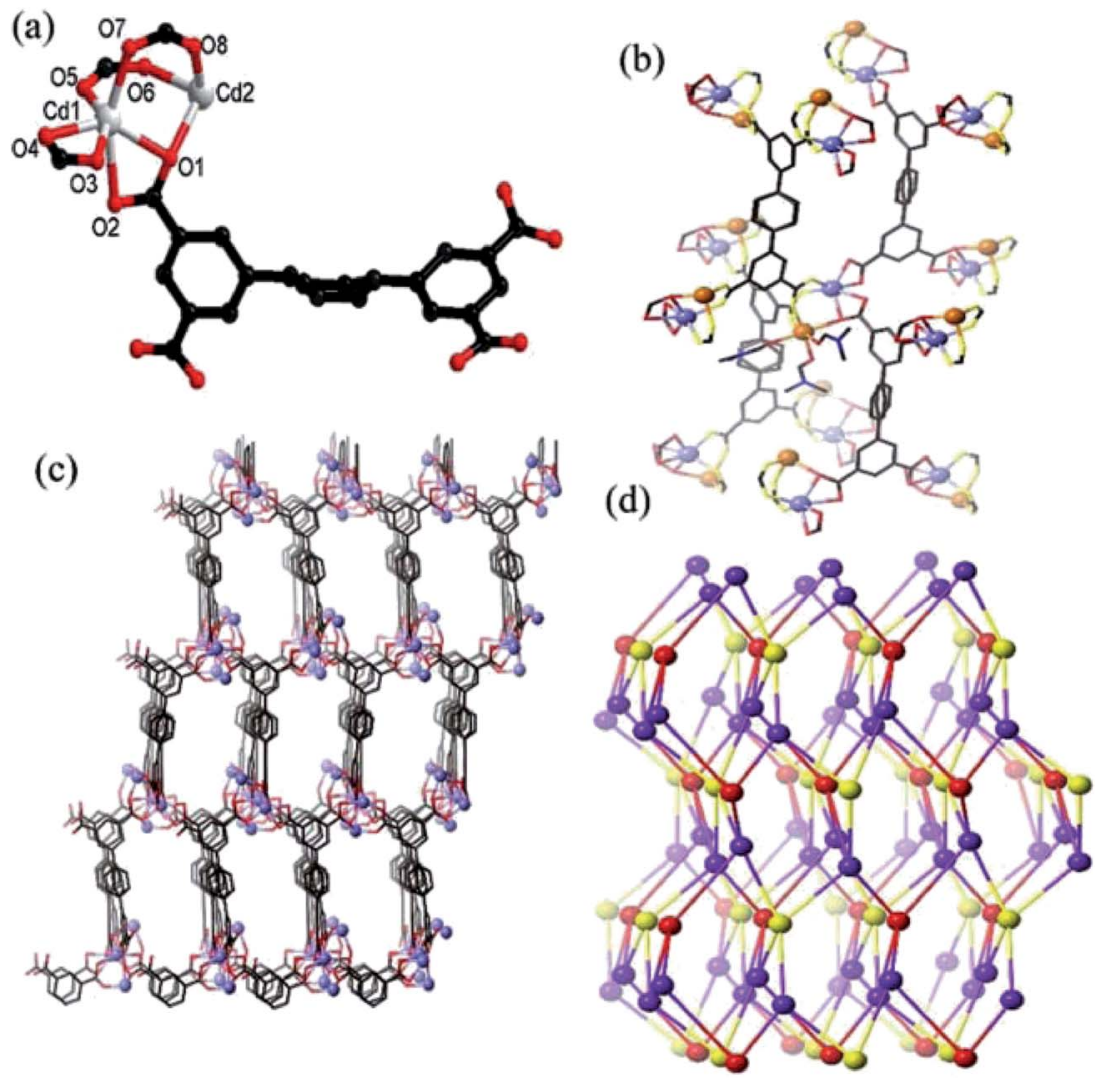

Fig. 1 (a) The perspective view of the coordination geometries of $\mathrm{Cd}(\Perp)$ centres in 1; (b) local coordination environments of both the ligand and the $\mathrm{Cd}_{2}$ metal cluster in 1. For clarity, the two unique $\mathrm{Cd}(\|)$ centers are shown in different colours (Cd1 in purple, Cd2 in orange), the oxygen atoms of the two unique $L$ ligands are shown in different colours (red or yellow). (Hydrogen atoms have been omitted for clarity. The central aromatic rings of both $L$ ligands are disordered over two positions.) (c) The perspective view of the 3D network in 1; (d) the underlying distorted diamond (dia) net in the structure of 1; red and yellow spheres represent the two different ligand nodes, while purple spheres represent the $\mathrm{Cd}_{2}$ cluster nodes (although all nodes are topologically equivalent).

and $\mathrm{H}_{4} \mathrm{~L}$ displayed strong emissions at $\sim 375 \mathrm{~nm}$ and $455 \mathrm{~nm}$, respectively but the intensity in emission of 1 was quite strong while that of $\mathrm{H}_{4} \mathrm{~L}$ was weak (Fig. S4†). The observed emission band in 1 could be tentatively attributed to the intra-ligand charge transfer (ILCT), which are constrained by coordination to $\mathrm{Cd}^{2+}$ with a relatively short distance between adjacent $\mathrm{H}_{4} \mathrm{~L}$ ligands, improving the weak interactions between them and thus change the emission. ${ }^{22}$ The intense emissive response of $\mathbf{1}$ in solid state stimulated us to explore its potential as possible fluorescent sensor for nitro-aromatic. The fluorescence property of $\mathbf{1}$ as suspensions in different solvents were examined and the suspension of 1 in nitrobenzene displayed the emission with lowest intensity. The observed emissive property of $\mathbf{1}$ as suspension in nitrobenzene was entirely different from the suspension of 1 in other solvents (Fig. 2a and S5 $†$ ). Hence the suspension of 1 in DMF was used for the detection of different aromatics and nitro-aromatics viz. 2,4,6-trinitrophenol (TNP), 2,4-dinitrotoluene (2,4-DNT), 2,6-dinitrotoluene (2,6-DNT), 2nitrotoluene (2-NT), 4-nitrotoluene (4-NT), 1,3-dinitrobenzene (1,3-DNB), 1,2,4-trimethylbenzene (1,2,4-TMB), 1,3,5-trimethylbenzene (1,3,5-TMB), $o$-nitrophenol (MNP), $p$-nitrophenol (PNP), 2,4-dinitrophenol (2,4-DNP). All the twelve aromatics compounds were capable of alleviating the emission intensity of
1 but to a different extent. The order of quenching efficiency of aromatics is 2,4-DNP $>\mathrm{PNP} \approx \mathrm{MNP}>\mathrm{TNP}>4-\mathrm{NT}>2$-NT $>2,4-$ DNT $>2,6$-DNT $>$ NB $>1,3-\mathrm{DNB}>1,2,4-\mathrm{TMB}>1,3,5-\mathrm{TMB}$ (Fig. 2b). ${ }^{23}$ Furthermore, the fluorescence intensity decreases steadily with concomitant increase in the concentrations of 2,4DNP, PNP, MNP and TNP. Upon addition of 90, 600, 240 and $500 \mathrm{ppm}$ of 2,4-DNP, PNP, MNP and TNP, respectively, the luminescent intensity of $\mathbf{1}$ was observed to be nearly nullified (Fig. 2c-e and S6-S9†). ${ }^{24}$

The other nitro-aromatics also displayed quenching effect to different extent on the fluorescence intensity of 1 (Fig. S10S21 $\dagger$ ). These results demonstrated that 1 possess good selectivity to detect 2,4-DNP, PNP, MNP and TNP in presence of other NACs (Fig. 2c-f and S6-S9†). The quantitative fluorescence quenching efficiency can be explained with the help of SternVolmer (SV) equation: $\left(I_{0} / I\right)=1+K_{\mathrm{sv}}[Q]$ and it is observed that the Stern-Volmer plots for 2,4-DNP, PNP, MNP and TNP are nearly linear when the concentrations of these NACs are at low concentrations with the corresponding $K_{\mathrm{sv}}$ values of $3.01 \times 10^{4}$, $7.47 \times 10^{3}, 6.55 \times 10^{3}$ and $1.08 \times 10^{4} \mathrm{M}^{-1}$, respectively (Fig. S6S9†). The 2,4-DNP, PNP, MNP and TNP detection limits are calculated to be $0.89,1.75,1.66$ and $1.64 \mathrm{ppm}$, respectively. Therefore, from this observation it can be inferred that $\mathbf{1}$ can be 

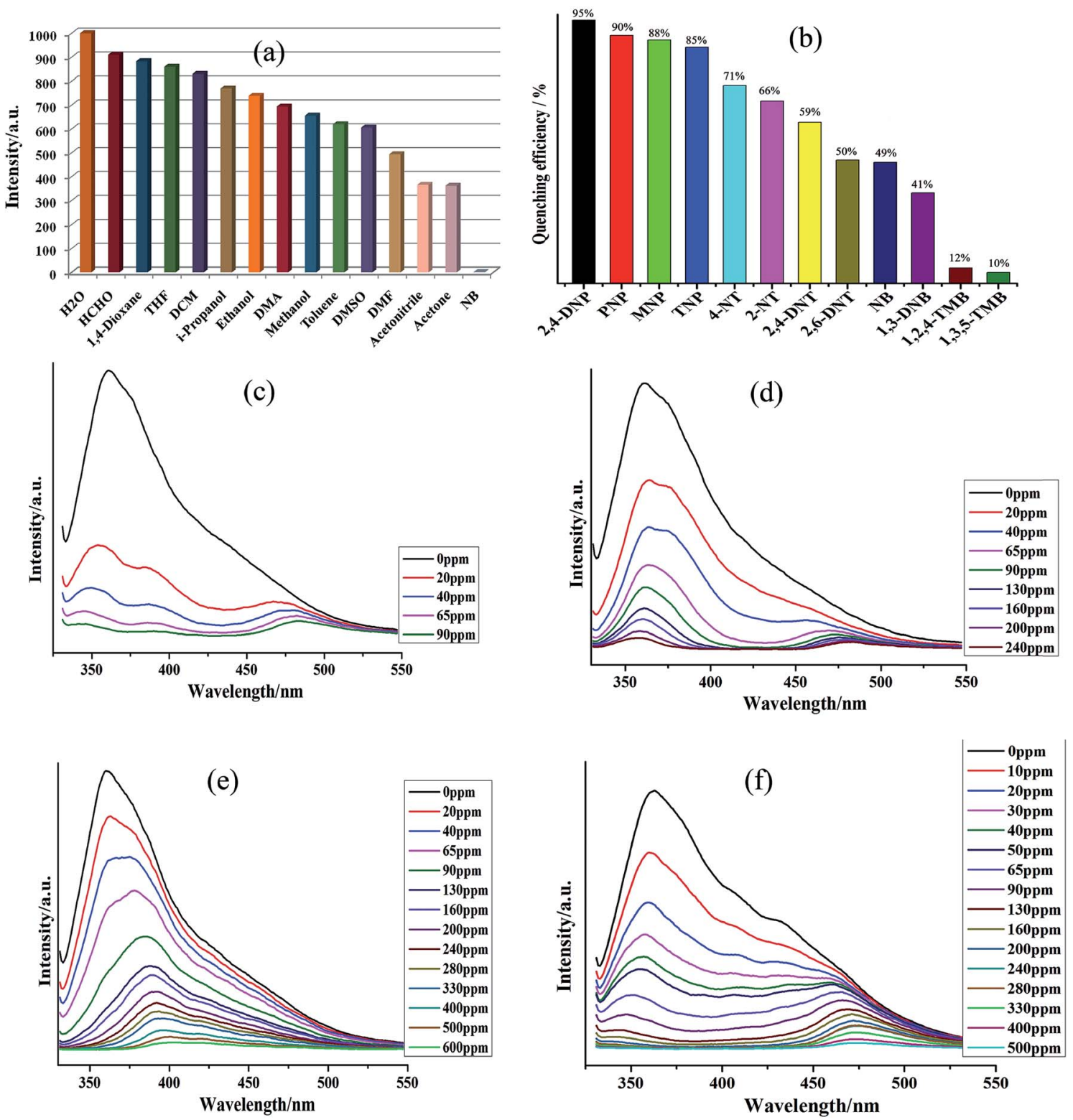

Fig. 2 (a) Photoluminescence intensity of 1 dispersed in different solvents, excited at $280 \mathrm{~nm}$; (b) the quenching efficiency of 1 dispersed in different explosives; (c-f) photoluminescence intensity of 1 dispersed in 2,4-DNP, PNP, MNP and TNP, respectively, excited at 280 nm.

used to distinguish NACs having varied number of -OH groups in a mixture comprising of other aromatics. Further to elucidate the detection mechanism of the sensors, the luminescence sensing of $\mathrm{H}_{4} \mathrm{~L}$ emulsions in the presence of 2,4-DNP were measured (Fig. S22†). The emission intensity of $\mathrm{H}_{4} \mathrm{~L}$ remained almost unchanged with different concentrations of 2,4-DNP suggesting that there may be interactions operating between 2,4-DNP and the $\mathrm{Cd}$ (II) centers of 1 and the variation in emission intensity are not related to the between 2,4-DNP and the ligands $\mathrm{H}_{4} \mathrm{~L}^{25-27}$ Also, the results of the powder X-ray diffraction (PXRD) patterns (Fig. S27d $\dagger$ ) indicated possible structural and/or symmetry changes within the crystal structure of 1 during the guest uptake.

The alleviation in the fluorescence intensity of $\mathbf{1}$ in the presence of ACs/NACs have been tried to be addressed with the aid of density functional theory calculations in which the HOMOLUMO energies of all the ACs/NACs, 1 as well as $\mathrm{H}_{4} \mathrm{~L}$ have been computed at the B3LYP level (Table 1, Fig. S28†). Our previous investigation $\mathrm{s}^{13}$ indicated that the probable reason lying behind the fluorescence quenching of $\mathbf{1}$ in presence of NACs will be the charge transfer from 1 to the LUMO of the NACs. Additionally, this charge transfer will be viable only when the LUMO of donor MOF 1 is positioned at energetically higher position in comparison to LUMO of the acceptor ACs/NACs. ${ }^{26-28}$ The computed HOMO-LUMO energies presented in Table 1 indicates that LUMO of all the NACs are lying at relatively lower energy when compared to donor $\mathbf{1}$ and as a consequence charge transfer from 1 to NACs can occur which may result in the decrease in fluorescence intensity in $\mathbf{1}$. But the observed order of fluorescence alleviation in $\mathbf{1}$ by these NACs is not fully consistent with LUMO 
Table 1 The HOMO-LUMO energies (in eV) for ligand $\left(\mathrm{H}_{4} \mathrm{~L}\right)$, MOF 1 and NACs

\begin{tabular}{lcc}
\hline Ligand/analyte & HOMO & LUMO \\
\hline $\mathrm{H}_{4} \mathrm{~L}$ & -6.36 & -1.83 \\
$\mathbf{1}$ & -5.73 & -2.09 \\
2-Nitrotoluene (2-NT) & -7.28 & -2.32 \\
4-Nitrotoluene (4-NT) & -7.36 & -2.32 \\
Nitrobenzene (NB) & -7.60 & -2.43 \\
2,6-Dinitrotoluene (2,6-DNT) & -7.91 & -2.87 \\
2,4-Dinitrotoluene (2,4-DNT) & -8.11 & -2.98 \\
1,3-Dinitrobenzene (1,3-DNB) & -8.42 & -3.14 \\
2,4,6-Trinitrophenol (TNP) & -8.54 & -3.55 \\
1,2,4-Trimethylbenzene (1,2,4-TMB) & -6.03 & 0.28 \\
1,3,5-Trimethylbenzene (1,3,5-TMB) & -6.18 & 0.26 \\
2,4-Dinitrophenol (2,4-DNP) & -7.62 & -3.33 \\
$o$-Nitrophenol (MNP) & -6.80 & -2.72 \\
p-Nitrophenol (PNP) & -7.43 & -2.39
\end{tabular}

energy trends of NACs, which indicates that the charge transfer is not the sole phenomenon for the alleviation in the fluorescence intensity and there may be the existence of electrostatic interaction between the $\mathbf{1}$ and NACs which is also contributing to the fluorescence quenching. ${ }^{13}$
The metal ion interaction studies were also performed by addition of $1.0 \times 10^{-4} \mathrm{M}$ nitrate salts of $\mathrm{Zn}^{2+}, \mathrm{Cd}^{2+}, \mathrm{Ca}^{2+}, \mathrm{Al}^{3+}$, $\mathrm{K}^{+}, \mathrm{Na}^{+}, \mathrm{Mg}^{2+}, \mathrm{Ni}^{2+}, \mathrm{Hg}^{2+}, \mathrm{Pb}^{2+}, \mathrm{Co}^{2+}, \mathrm{Cu}^{2+}, \mathrm{Ag}^{+}$and $\mathrm{Fe}^{3+}$ to 1$\mathrm{H}_{2} \mathrm{O}$ emulsions. The fluorescence intensities of $\mathrm{M}^{n+}$ @1 emulsions were recorded and compared (Fig. 3a and S23†) which indicated markedly different fluorescence intensities. $\mathrm{Zn}^{2+}$, $\mathrm{Cd}^{2+}$ and $\mathrm{Al}^{3+}$ metal ions exhibited positive effects on the luminescent intensity, while others demonstrated different levels of quenching effect on luminescent intensity, especially $\mathrm{Fe}^{3+}$ exhibiting the most significant quenching effect. ${ }^{28}$ The sensitivity of $\mathbf{1}$ towards $\mathrm{Fe}^{3+}$ was also explored further by performing the concentration gradient experiments by using the $\mathrm{Fe}^{3+}$ solutions having the concentration ranging from 0 to $600 \mathrm{ppm}$. The concentration gradient experiments indicated that the luminescence intensity of $\mathrm{Fe}^{3+} @ 1$ gradually decreases with the increase in concentration of $\mathrm{Fe}^{3+}$ (Fig. 3a). Furthermore, the fluorescence lifetime measurements indicated that the fluorescence lifetime of $\mathbf{1}$ which was in isolated state was 110.41 ns gets reduced to $8.19 \mathrm{~ns}$ in presence of $1.0 \mathrm{mM} \mathrm{Fe}$ (Fig. S24†). Hence, it can be inferred that energy transfer may be responsible for the quenching phenomenon. ${ }^{29}$ To elucidate the possible mechanism for such fluorescence quenching by $\mathrm{Fe}^{3+}$ ion, O 1s X-ray photoelectron spectroscopic (XPS) studies were

(a)

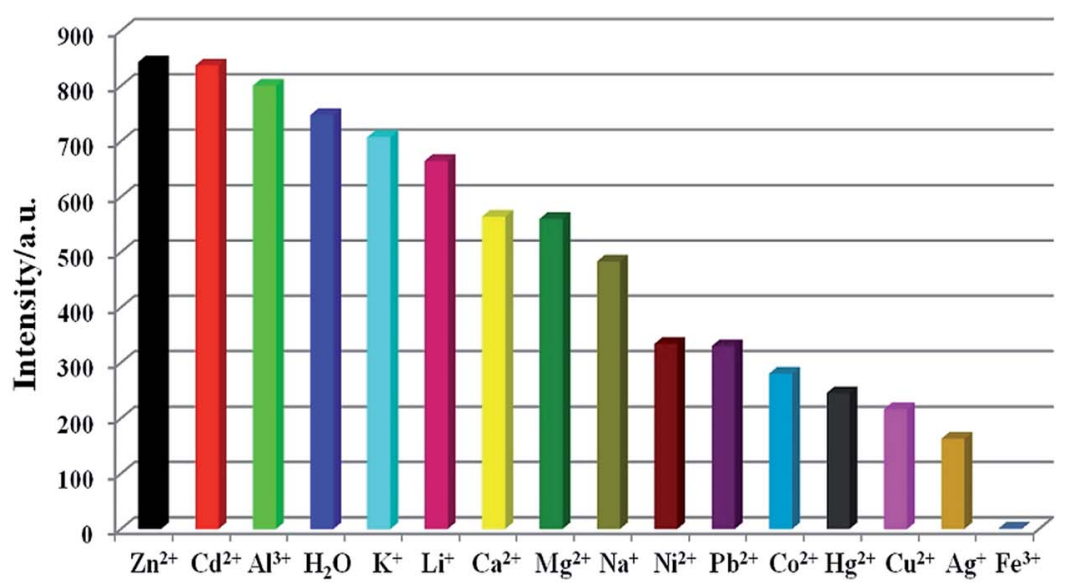

(b)

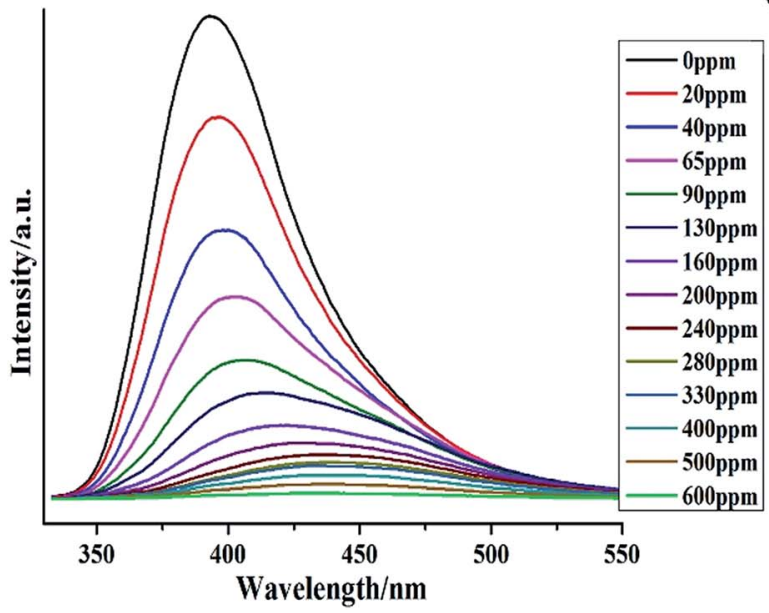

(c)

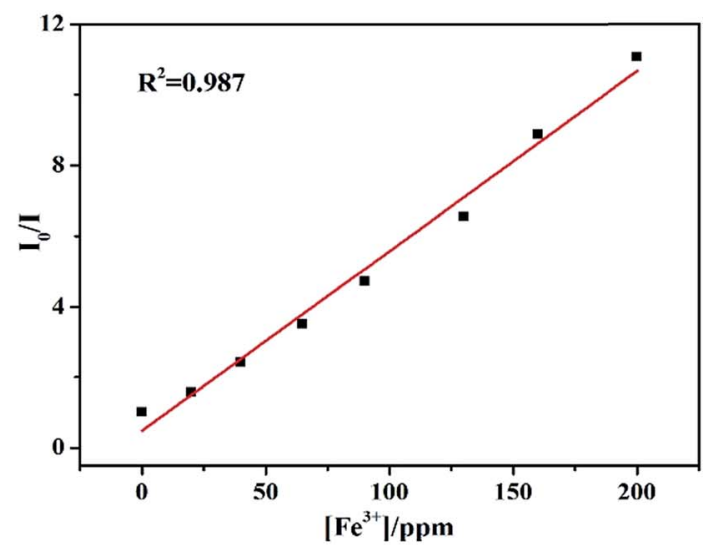

Fig. 3 (a) Photoluminescence intensity of 1 dispersed in different metal ions solutions, excited at 280 nm; (b) emissive response spectra of 1 for $\mathrm{Fe}^{3+}$ in $\mathrm{H}_{2} \mathrm{O}$ solution with different concentrations; (c) the Stern-Volmer plot for $\mathrm{Fe}^{3+}$. 

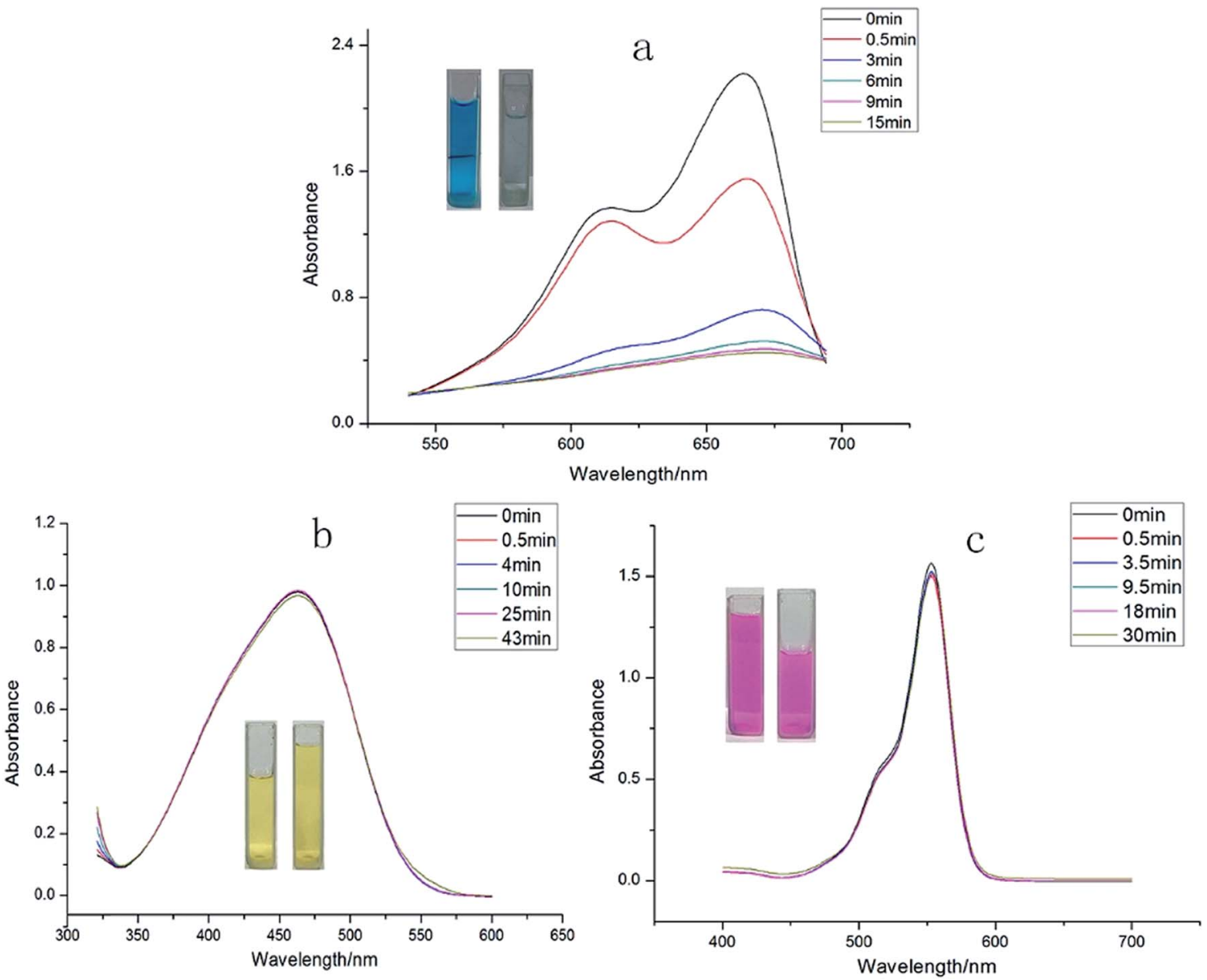

Fig. 4 The periodic UV-vis spectroscopy showing the adsorption capability of 1 toward (a) MB dye, (b) MO dyes, and (c) Rh B dye.

carried out on $\mathbf{1}$ and $\mathrm{Fe}^{3+} @ 1$. XPS investigation indicated that the $\mathrm{O} 1 \mathrm{~s}$ peak observed at $531.62 \mathrm{eV}$ for the free oxygen atoms of the carboxylate ligand in 1 gets shifted to $531.74 \mathrm{eV}$ on the addition of $\mathrm{Fe}^{3+}$ (Fig. S25a $\uparrow$ ), which may indicate the weak binding of oxygen atoms to $\mathrm{Fe}^{3+}$. The powder X-ray diffraction (PXRD) patterns (Fig. S27c $\dagger$ ) indicated possible structural and/ or symmetry changes within the crystal structure of $\mathbf{1}$ upon dispersion in $\mathrm{Fe}^{3+}$ solutions.

The Stern-Volmer plots for $\mathrm{Fe}^{3+}$ are nearly linear at low concentrations $\left(R^{2}=0.987\right)$ with the $K_{\mathrm{sv}}$ value of $2.06 \times 10^{4} \mathrm{M}^{-1}$ (Fig. 3b). The $\mathrm{Fe}^{3+}$ detection limit is calculated to be $1.24 \mathrm{ppm}$. $\mathrm{Fe}^{3+}$ ion with the larger $K_{\mathrm{sv}}$ value demonstrates its quenching effect on the luminescent intensity of $\mathbf{1 . 9 9 , 3 0}$ As presented in Table S3, $\uparrow$ most of the reported MOFs can detect $\mathrm{Fe}^{3+}$ in the concentration ranging between $10^{-3}$ to $10^{-5} \mathrm{M}$, and the lowest detected concentration of $\mathrm{Fe}^{3+}$ was recorded $c a .0 .9 \times 10^{-6} \mathrm{M}^{29 b}$ In comparison to these reports, $\mathbf{1}$ also display potentially high sensitivity and selectivity for $\mathrm{Fe}^{3+}$.

\section{Selective adsorption of organic dye}

We also attempted to probe $\mathbf{1}$ as an adsorbent for different organic dyes present in the waste-water. As a model system three types of dye (methylene blue (MB), methyl orange (MO) and rhodamine $\mathrm{B}(\mathrm{Rh} \mathrm{B})$ ) with different size and charges were chosen as adsorbates. ${ }^{31}$ In a typical experiment, $30 \mathrm{mg}$ of adsorbent 1 was immersed in $30 \mathrm{~mL}$ of aqueous dye solution containing $1 \times 10^{-5} \mathrm{~mol} \mathrm{~L}^{-1}$ of dye at room temperature and the mixture was continuously stirred. During the given time period, the ability of $\mathbf{1}$ to adsorb dyes from aqueous solution was determined through UV-vis spectroscopy. The UV-vis spectroscopy results showed that $\mathbf{1}$ possesses excellent capacity to adsorb MB (Fig. 4) while its ability to adsorb MO and Rh B was almost negligible. A plausible mechanism of the selective adsorption of MB by 1 could be explained through size matching of the MB molecule with the pore size of $1{ }^{32}$ The adsorption rate is greater than $75 \%$ in the first $30 \mathrm{~s}$, moreover, it is worthy to mention that 1 can adsorb completely MB within 15 minutes.

The removed quantity of MB by 1 has been calculated using the following equation. ${ }^{33-36}$

$$
Q_{\mathrm{eq}}=\frac{C_{0}-C_{\mathrm{eq}}}{m} V
$$

The equation indicates that every gram of $\mathbf{1}$ can adsorb $68.5 \mathrm{mg}$ of MB. This fast and high-capacity adsorption process is also very important for adsorbents in practical wastewater treatment. ${ }^{33}$ The color of the crystals of $\mathbf{1}$ was found to change from colorless to blue after adsorption (Fig. 5), which indicated 


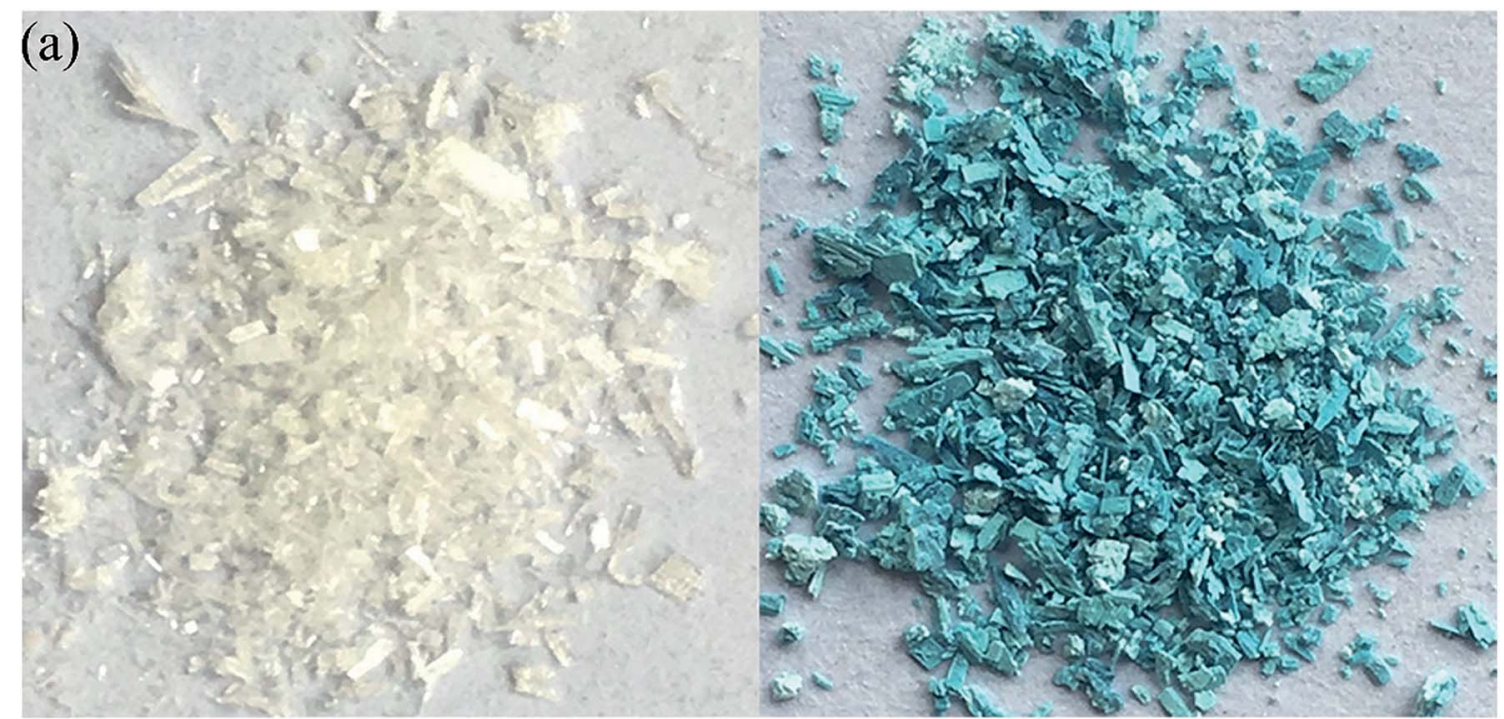

(b)

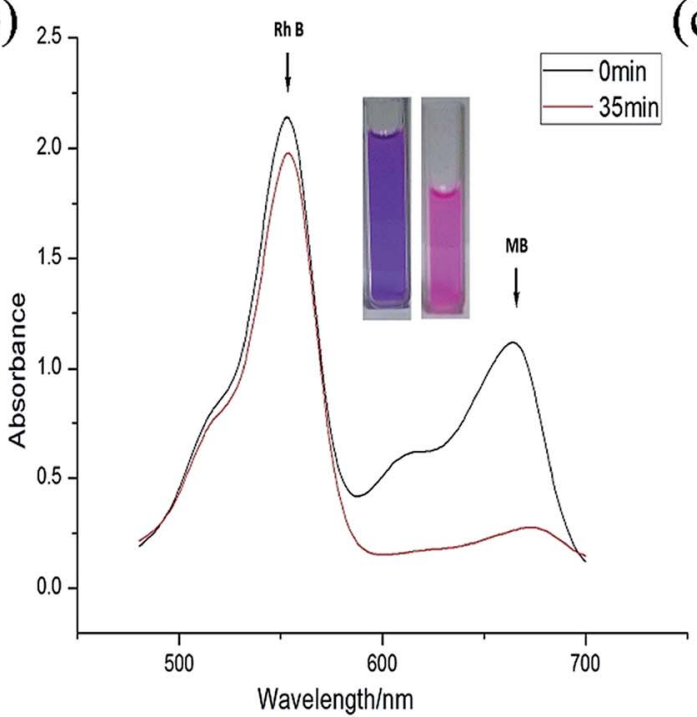

(c)

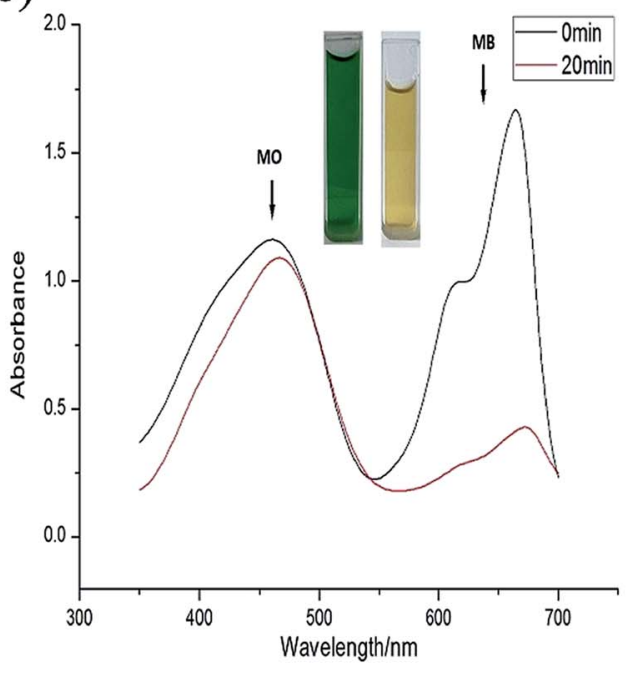

Fig. 5 (a) The color of 1 before (left) and after (right) adsorption of MB dye; (b) the adsorption capability of 1 toward Rh B + MB mixed dyes; (c) MB + MO mixed dyes.

Table 2 Kinetics parameters for different kinetics model for MB adsorption using 1

\begin{tabular}{llc}
\hline Model & Parameter & $\mathrm{MB}$ \\
\hline Pseudo-first-order & $K_{1}\left(\mathrm{~min}^{-1}\right)$ & 0.670 \\
& $q_{\mathrm{e}}\left(\mathrm{mg} \mathrm{g}^{-1}\right)$ & 47.55104 \\
& $R$ & 0.97673 \\
Pseudo-second-order & $K_{2}\left(\mathrm{~g} \mathrm{mg}^{-1} \mathrm{~min}^{-1}\right)$ & 0.01379 \\
& $q_{\mathrm{e}}\left(\mathrm{mg} \mathrm{g}^{-1}\right)$ & 39.573 \\
Second-order & $R$ & 0.99446 \\
& $K_{3}\left(\mathrm{~g} \mathrm{mg}^{-1} \mathrm{~min}^{-1}\right)$ & 2.17786 \\
Intraparticle diffusion & $q_{\mathrm{e}}\left(\mathrm{mg} \mathrm{g}^{-1}\right)$ & 0.1483 \\
& $R$ & 0.49404 \\
& $K_{4}\left(\mathrm{mg} \mathrm{g}^{-1} \mathrm{~min}^{-1 / 2}\right)$ & 10.9904 \\
& $C$ & 2.44444 \\
& $R$ & 0.92411
\end{tabular}

that MB molecules entered into the crystal lattice of 1 instead of merely being getting adsorbed on the surface of the crystals.

To validate whether 1 possesses the ability to separate MB from a mixed-dye solution, we utilized 1 to capture MB from mixed-dye aqueous solutions. The UV-vis spectra were recorded after soaking 1 in mixed dye aqueous solutions comprising of $\mathrm{Rh} \mathrm{B}+\mathrm{MB}$ as well as $\mathrm{MB}+\mathrm{MO}$ and it was observed that in both the cases only MB molecules could efficiently be adsorbed by 1 over a period of time (Fig. 5a and b), while Rh B and MO could not be encapsulated by 1 . As shown in the photographs (the inserted pictures in Fig. $5 \mathrm{~b}$ and $\mathrm{c}$ ), after soaking 1 in the mixeddye aqueous solution, the color of the solution changed but finally retained the characteristic color of Rh B and MO. These results also confirms that $\mathbf{1}$ could effectively and selectively adsorb MB molecules into its framework and leaving $\mathrm{Rh} \mathrm{B}$ as well as MO molecules in solution. Furthermore, the adsorption capacity of the $\mathbf{1}$ is fully maintained after recycling the MOF for 

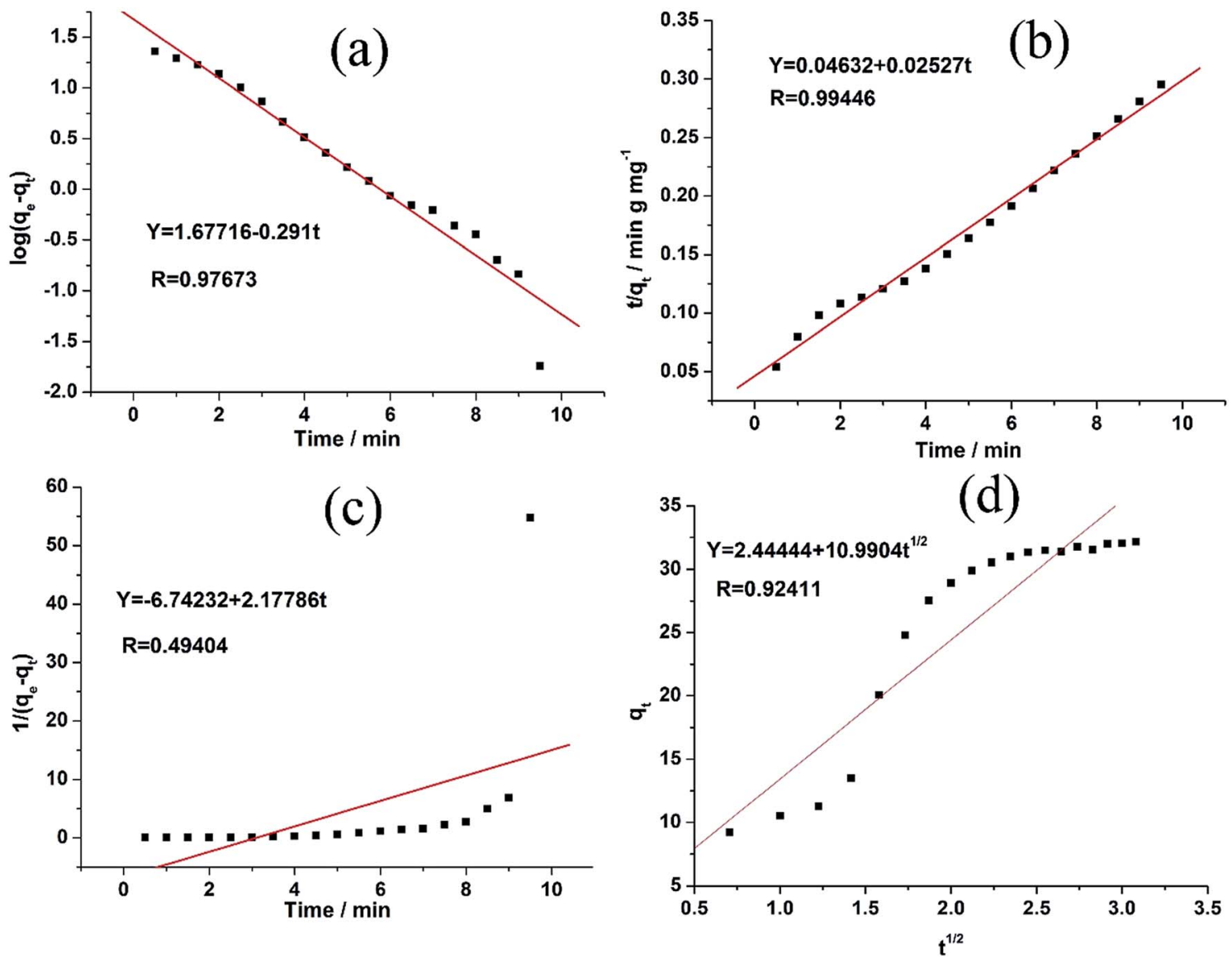

Fig. 6 (a-d) The adsorption kinetics of MB onto 1 using pseudo-second-order using different models, respectively.

five times. After adsorption, the MB@1 can expediently release MB through simply washing the sample MB@1 with ethanol after recycling 5 times and after releasing MB 1 again displayed almost identical rapid and quantitative adsorption of $\mathrm{MB}$ (Fig. S29†). Thus, $\mathbf{1}$ acts as an excellent candidate as a selective adsorption material, which can be applied practically to adsorb MB in waste-water containing mixture of organic dyes.

\section{Adsorption kinetics}

The rate of dye adsorption by $\mathbf{1}$ depends on the contact time of $\mathbf{1}$ and dye solution as well as on the diffusion process. During the process of adsorption, $\mathrm{MB}$ molecules migrate to the outer surface of 1, diffuse into the layers of the MOF, and are then adsorbed via pore diffusion. To further explore the adsorption kinetics, pseudo-first order, pseudo-second-order, second-order and intraparticle diffusion kinetics models were employed. The constants of all of the kinetics models were calculated by using equations.

The pseudo-first-order rate equation:

$$
\log \left(q_{\mathrm{e}}-q_{t}\right)=\log q_{\mathrm{e}}-\frac{K_{1}}{2.303} t
$$

The pseudo-second-order rate equation:

$$
\frac{t}{q_{t}}=\frac{1}{K_{2} q_{\mathrm{e}}^{2}}+\frac{t}{q_{\mathrm{e}}}
$$

The second-order rate equation:

$$
\begin{aligned}
& \frac{1}{q_{\mathrm{e}}-q_{t}}=\frac{1}{q_{\mathrm{e}}}+K_{3} t \\
& q_{t}=K_{4} t^{1 / 2}+C
\end{aligned}
$$

As evident from the Table 2 and Fig. 6, there are four $R^{2}$ for MB obtained from the aforementioned equations. The fit of the experimental results show that the pseudo-second-order model possesses the highest $R^{2}$ value compared to the other adsorption kinetics models. ${ }^{32,36}$ Therefore, the results indicate that the adsorption kinetics can be best described by a pseudo-second order model.

\section{Conclusion}

Our results indicated that the fluorescent MOF 1 reported herein possesses dual sensing ability for nitro-aromatics and ferric. The presented investigation indicated that the tetracarboxylate ligand terphenyl-3,3",5,5"-tetracarboxylic acid $\left(\mathrm{H}_{4} \mathrm{~L}\right)$ because of its symmetric structure provides a new avenue to produce a new 3D microporous framework with 4-connected Dia topology based on $\left\{\mathrm{Cd}_{2}\left(\mathrm{CO}_{2}\right)_{4}\right\}$ subunits. The theoretical calculations indicated that not only charge transfer rather electrostatic interaction between the $\mathbf{1}$ and nitro-aromatic 
compounds also contribute towards the exceptional selective fluorescence intensity alleviation. Also, $\mathbf{1}$ acted as an excellent and selective adsorbent material for organic dye methylene blue (MB) and can be utilized repeatedly for effective adsorption of MB from waste-water without significant alleviation in the adsorption capacity. It is apparent from the investigation that by choosing suitable symmetric polycarboxylate ligands one can develop LMOFs for selective sensing as well dye adsorption applications.

\section{Conflicts of interest}

There are no conflicts to declare.

\section{Acknowledgements}

This work was partially supported by the grants from the Science and Technology Plan Projects of Dongguan (2016108101005), Sichuan University of Science and Engineering (No. 2015RC26), Innovative Entrepreneurial Training Plan of undergraduates in Guangdong Province (20170571005, 20170571007, 201705710011, 20170571016, 20170571019, 20170571012, 20170571060, 20170571078), the Public Research and Capacity Building Projects of Department of Guangdong Province (2017A010103022), Natural Science Foundation of Guangdong Province (2017A030313079) and Science Foundation funded project of Guangdong Medical University (Z2016001 and M2016023) and Thanks for Prof. S. R. Batten for structure analysis.

\section{References}

1 (a) M. D. Allendorf, C. A. Bauer, R. K. Bhakta and R. J. T. Houk, Chem. Soc. Rev., 2009, 38, 1330; (b) J. Heine and K. M. Buschbaum, Chem. Soc. Rev., 2013, 42, 9232; (c) X. D. Zhang, Y. F. Gao, H. T. Liu and Z. L. Liu, CrystEngComm, 2015, 17, 6037.

2 (a) L. Liu, X. Chen, J. Qiu and C. Hao, Dalton Trans., 2015, 44, 2897; (b) G. A. Eiceman and J. A. Stone, Anal. Chem., 2004, 76, 390; (c) M. E. Germain and M. J. Knapp, Chem. Soc. Rev., 2009, 38, 2543; (d) D. B. Hall, R. E. Holmlin and J. K. Barton, Nature, 1996, 382, 731.

3 (a) S. W. Thomas, G. D. Joly and T. M. Swager, Chem. Rev., 2007, 107, 1339; (b) X. Liu, Z. Xiao, J. Xu, W. Xu, P. Sang, L. Zhao, H. Zhu, D. Sun and W. Guo, J. Mater. Chem. A, 2016, 4, 13844; (c) J. R. Li, J. Sculley and H. C. Zhou, Chem. Rev., 2012, 112, 869; (d) B. L. Chen, S. Xiang and G. Qian, Acc. Chem. Res., 2010, 43, 1115.

4 L. E. Kreno, K. Leong, O. K. Farha, M. Allendorf, D. R. P. Van and J. T. Hupp, Chem. Rev., 2012, 112, 1105.

5 (a) L. Di, J. J. Zhang, S. Q. Liu, J. Ni, H. Zhou and Y. J. Sun, Cryst. Growth Des., 2016, 16, 4539; (b) Z. J. Lin, J. Lu, M. Hong and R. Cao, Chem. Soc. Rev., 2014, 43, 5867; (c) N. Stock and S. Biswas, Chem. Rev., 2012, 112, 933.

6 (a) J. Wang, Y. Li, M. Jiang, Y. Liu, L. Zhang and P. Wu, Chem.-Eur. J., 2016, 22, 13023; (b) W. Lu, Z. Wei, Z. Y. Gu, T. F. Liu, J. Park, J. Park, J. Tian, M. Zhang, Q. Zhang,
T. Gentle, M. Bosch and H. C. Zhou, Chem. Soc. Rev., 2014, 43, 5561; (c) H. C. Zhou and S. Kitagawa, Chem. Soc. Rev., 2014, 43, 5415; (d) A. J. Lan, K. H. Li, H. H. Wu, D. H. Olson, T. J. Emge, W. Ki, M. C. Hong and J. Li, Angew. Chem., Int. Ed., 2009, 48, 2334.

7 G. J. Zhao and K. L. Han, Acc. Chem. Res., 2012, 45, 404.

8 B. L. Chen, S. Ma, F. Zapata, E. B. Lobkovsky and J. Yang, Inorg. Chem., 2006, 45, 5718.

9 (a) B. Gole, A. K. Bar and P. S. Mukherjee, Chem.-Eur. J., 2014, 20, 2276; (b) Z. C. Hu, B. J. Deibert and J. Li, Chem. Soc. Rev., 2014, 43, 5815.

10 Y. Cui, Y. Yue, G. Qian and B. L. Chen, Chem. Rev., 2012, 112, 1126.

11 (a) E. Haque, J. W. Jun and S. H. Jhung, J. Hazard. Mater., 2011, 185, 507; (b) M. Liang and J. Chen, Chem. Soc. Rev., 2013, 42, 3453; (c) W. Fan, W. Gao, C. Zhang, W. W. Tjiu, J. Pan and T. Liu, J. Mater. Chem., 2012, 22, 25108.

12 (a) Y. Al-Degs, M. A. M. Khraisheh, S. J. Allen and M. N. Ahmad, Water Res., 2000, 34, 927; (b) A. G. Espantaléon, J. A. Nieto, M. Fernández and A. Marsal, Appl. Clay Sci., 2003, 24, 105; (c) C. K. Lee, S. S. Liu, L. C. Juang, C. C. Wang, K. S. Lin and M. D. Lyu, J. Hazard. Mater., 2007, 147, 997; (d) Y. Yu, Y. Y. Zhuang, Y. Li and M. Q. Qiu, Ind. Eng. Chem. Res., 2002, 41, 1589.

13 T. Gadzikwa, O. K. Farha, C. D. Malliakas, M. G. Kanatzidis, J. T. Hupp and S. T. Nguyen, J. Am. Chem. Soc., 2009, 131, 13613.

14 (a) J. Q. Liu, G. L. Liu, C. Y. Gu, W. C. Liu, J. W. Xu, B. H. Li and W. J. Wang, J. Mater. Chem. A, 2016, 4, 11630; (b) J. Q. Liu, J. Wu, F. M. Li, W. C. Liu, B. H. Li, J. Wang, Q. L. Li, R. Yadav and A. Kumar, RSC Adv., 2016, 6, 31161; (c) B. H. Li, J. Wu, J. Q. Liu, C. Y. Gu, J. W. Xu, M. M. Luo, R. Yadav, A. Kumar and S. R. Batten, ChemPlusChem, 2016, 81, 885; (d) J. Q. Liu, G. P. Li, W. C. Liu, Q. L. Li, B. H. Li, R. W. Gable, L. Hou and S. R. Batten, ChemPlusChem, 2016, 81, 1299; (e) J. Wang, X. R. Wu, J. Q. Liu, B. H. Li, A. Singh, A. Kumar and S. R. Batten, CrystEngComm, 2017, 19, 3519; (f) L. Lu, J. Wang, B. Xie, J. Q. Liu, R. Yadav, A. Singh and A. Kumar, New J. Chem., 2017, 41, 3537.

15 G. M. Sheldrick, Acta Crystallogr., Sect. A: Found. Adv., 2015, $7,3$.

16 A. L. Spek, J. Appl. Crystallogr., 2003, 36, 7.

17 (a) A. D. Becke, J. Chem. Phys., 1993, 98, 5648; (b) C. T. Lee, W. T. Yang and R. G. Parr, Phys. Rev. B: Condens. Matter Mater. Phys., 1998, 37, 785; (c) M. J. Frisch, G. W. Trucks, H. B. Schlegel, G. E. Scuseria, M. A. Robb, J. R. Cheeseman, J. A. Montgomery, T. Vreven Jr, K. N. Kudin, J. C. Burant, J. M. Millam, S. S. Iyengar, J. Tomasi, V. Barone, B. Mennucci, M. Cossi, G. Scalmani, N. Rega, G. A. Petersson, H. Nakatsuji, M. Hada, M. Ehara, K. Toyota, R. Fukuda, J. Hasegawa, M. Ishida, T. Nakajima, Y. Honda, O. Kitao, H. Nakai, M. Klene, X. Li, J. E. Knox, H. P. Hratchian, J. B. Cross, V. Bakken, C. Adamo, J. Jaramillo, R. Gomperts, R. E. Stratmann, O. Yazyev, A. J. Austin, R. Cammi, C. Pomelli, J. W. Ochterski, P. Y. Ayala, K. Morokuma, G. A. Voth, P. Salvador, J. J. Dannenberg, V. G. Zakrzewski, S. Dapprich, 
A. D. Daniels, M. C. Strain, O. Farkas, D. K. Malick, A. D. Rabuck, K. Raghavachari, J. B. Foresman, J. V. Ortiz, Q. Cui, A. G. Baboul, S. Clifford, J. Cioslowski, B. B. Stefanov, G. Liu, A. Liashenko, P. Piskorz, I. Komaromi, R. L. Martin, D. J. Fox, T. Keith, M. A. AlLaham, C. Y. Peng, A. Nanayakkara, M. Challacombe, P. M. W. Gill, B. Johnson, W. Chen, W. M. Wong, C. Gonzalez and J. A. Pople, Gaussian, Inc., Wallingford CT, 2009.

18 J. K. Schnobrich, O. Lebel, K. A. Cychosz, A. Dailly and A. J. Matzger, J. Am. Chem. Soc., 2010, 132, 13941.

19 (a) S. Yang, X. Lin, A. J. Blake, G. S. Walker, P. Hubberstey, N. R. Champness and M. Schröder, Nat. Chem., 2009, 1, 487; (b) M. Li, D. Li, M. O'Kee and O. M. Yaghi, Chem. Rev., 2014, 114, 1343; (c) X. Lin, I. Telepeni, A. J. Blake, A. Dailly, C. M. Brown, J. M. Simmons, M. Zoppi, G. S. Walker, K. M. Thomas, T. J. Mays, P. Hubberstey, N. R. Champness and M. Schröder, J. Am. Chem. Soc., 2009, 131, 2159; (d) X. Rao, J. Cai, J. Yu, Y. He, C. Wu, W. Zhou, T. Yildirim, B. Chen and G. Qian, Chem. Commun., 2013, 49, 6719.

20 (a) Y. Cui, Y. Yue, G. Qian and B. Chen, Chem. Rev., 2012, 112, 1126; (b) M. D. Allendorf, C. A. Bauer, R. K. Bhakta and R. J. T. Houk, Chem. Soc. Rev., 2009, 38, 1330; (c) K. Jayaramulu, P. Kanoo, S. J. George and T. K. Maji, Chem. Commun., 2010, 46, 7906; (d) R. C. Huxford, J. D. Rocca and W. B. Lin, Curr. Opin. Chem. Biol., 2010, 14, 262.

21 (a) K. Jayaramulu, R. P. Narayanan, S. J. George and T. K. Maji, Inorg. Chem., 2012, 51, 10089; (b) J. K. Ayaramulu, P. Kanoo, S. J. George and T. K. Maji, Chem. Commun., 2010, 46, 7906.

22 (a) X. H. Zhou, L. Li, H. H. Li, A. Li, T. Yang and W. Huang, Dalton Trans., 2013, 42, 12403; (b) Y. Chen, Z. Li, Q. Liu, Y. Shen, X. Wu, D. Xu, X. Ma, L. Wang, Q. H. Chen, Z. Zhang and S. Xiang, Cryst. Growth Des., 2015, 15, 3847; (c) X. D. Zhu, Y. Li, W. X. Zhou, R. M. Liu, Y. J. Ding, J. Lü and D. M. Proserpiocd, CrystEngComm, 2016, 18, 4530.

23 (a) S. Sanda, S. Parshamoni, S. Biswas and S. Konar, Chem. Commun., 2015, 51, 6576; (b) L. H. Cao, F. Shi, W. M. Zhang, S. Q. Zang and T. C. W. Mak, Chem.-Eur. J., 2015, 21, 15705; (c) D. K. Singha, S. Bhattachary, P. Majee, S. K. Mondal, M. Kumara and P. Mahata, J. Mater. Chem. A, 2014, 2, 20908; (d) Z. Q. Shi, Z. J. Guo and H. G. Zheng, Chem. Commun., 2015, 51, 8300; (e) S. S. Nagarkar, B. Joarder, A. K. Chaudhari, S. Mukherjee and S. K. Ghosh, Angew. Chem., Int. Ed., 2013, 52, 2881; (f) S. S. Nagarkar, A. V. Desai and S. K. Ghosh, Chem. Commun., 2014, 50,
8915; $(g)$ B. Gole, A. K. Bar and P. S. Mukherjee, Chem.Eur. J., 2014, 20, 2276; (h) S. R. Zhang, D. Y. Du, J. S. Qin, S. J. Bao, S. L. Li, W. W. He, Y. Q. Lan, P. Shen and Z. M. Su, Chem.-Eur. J., 2014, 20, 3589; (i) Y. N. Gong, Y. L. Huang, L. Jiang and T. B. Lu, Inorg. Chem., 2014, 53, 9457.

24 (a) X. Zhou, H. Li, H. Xiao, L. Li, Q. Zhao, T. Yang, J. Zuo and W. Huang, Dalton Trans., 2013, 42, 5718; (b) L. Sun, H. Xing, J. Xu, Z. Liang, J. Yu and R. Xu, Dalton Trans., 2013, 42, 5508; (c) X. Guo, G. Zhu, Q. Fang, M. Xue, G. Tian, J. Sun, X. Li and S. Qiu, Inorg. Chem., 2005, 44, 3850; (d) S. Barman, J. Anand Garg, O. Blacque, K. Venkatesan and H. Berke, Chem. Commun., 2012, 48, 11127.

25 C. Zhang, L. Sun, Y. Yan, J. Li, X. Song, Y. Liu and Z. Liang, Dalton Trans., 2015, 44, 230.

26 (a) X. Z. Song, S. Y. Song, S. N. Zhao, Z. M. Hao, M. Zhu, X. Meng, L. L. Wu and H. J. Zhang, Adv. Funct. Mater., 2014, 24, 4034; (b) J. D. Xiao, L. G. Qiu, F. Ke, Y. P. Yuan, G. S. Xu, Y. M. Wang and X. Jiang, J. Mater. Chem. A, 2013, 1,8745 .

27 L. V. Meyer, F. Schönfeld and K. Müller-Buschbaum, Chem. Commun., 2014, 50, 8093.

28 (a) Y. Zhou, H. H. Chen and B. Yan, J. Mater. Chem. A, 2014, 2, 13691; (b) C. X. Yang, H. B. Ren and X. P. Yan, Anal. Chem., 2013, 85, 7441; (c) S. Pramanik, C. Zheng, X. Zhang, T. J. Emge and J. Li, J. Am. Chem. Soc., 2011, 133, 4153; (d) S. Xiang, W. Zhou, Z. Zhang, M. A. Green, Y. Liu and B. Chen, Angew. Chem., Int. Ed., 2010, 49, 4615.

29 (a) J. Zhang, B. Zheng, T. T. Zhao, G. H. Li, Q. S. Huo and Y. L. Liu, Cryst. Growth Des., 2014, 14, 2394; (b) J. Wang, Y. Li, M. Jiang, Y. H. Liu, L. W. Zhang and P. Y. Wu, Chem.-Eur. J., 2016, 22, 13023.

30 J. S. Qin, S. R. Zhang, D. Y. Du, P. Shen, S. J. Bao, Y. Q. Lan and Z. M. Su, Chem.-Eur. J., 2014, 20, 5625.

31 X. Zhang, Y. Gao, H. Liu and Z. Liu, CrystEngComm, 2015, 17, 6037.

32 S. Legergren, About the Theory of so-Called Adsorption of Soluble Substances, K. Sven. Vetenskapsakad. Handl., 1898, 24,1 .

33 Y. S. Ho and G. McKay, Process Biochem., 1999, 34, 451.

34 Y. S. Ho, Water Res., 2006, 40, 119.

35 W. J. Weber and J. C. Morris, J. Sanit. Eng. Div., Am. Soc. Civ. Eng., 1963, 89, 31.

36 L. Liu, Z. Y. Gao, X. P. Su, X. Chen, L. Jiang and J. M. Yao, ACS Sustainable Chem. Eng., 2015, 3, 432. 